\title{
Enhancing resilience in urban water systems for future cities
}

\author{
Seith N. Mugume a, Kegong Diao, Maryam Astaraie-Imani, Guangtao Fu, Raziyeh Farmani, \\ David Butler \\ ${ }^{a}$ University of Exeter, Centre for Water Systems, College of Engineering, Mathematics and Physical \\ Sciences, North Park Road, Exeter, EX4 4QF, United Kingdom; Tel: +44 (0)1392 723600, E-mail: \\ snm205@exeter.ac.uk
}

\begin{abstract}
In future cities, urban water systems (UWSs) should be designed not only for safe provision of services but should also be resilient to emerging or unexpected threats that lead to catastrophic system failure impacts and consequences. Resilience can potentially be built into UWSs by implementing a range of strategies, for example by embedding redundancy and flexibility in system design or rehabilitation to increase their ability to maintain acceptable customer service levels during unexpected system failures. In this work, a new resilience analysis is carried out to investigate the performance of a water distribution system (WDS) and an urban drainage system (UDS) during pipe failure scenarios. Using simplified synthetic networks, the effect of implementing adaptation (resilient design) strategies on minimising the loss of system functionality and cost of UWSs is investigated. Study results for the WDS case study show that the design strategy in which flexibility is enhanced ensures that all customers are served during single pipe failure scenarios. The results of the UDS case study indicate that the design strategy incorporating upstream distributed storage tanks minimizes flood volume and mean duration of nodal flooding by $50.1 \%$ and $46.7 \%$ respectively even when system functionality is significantly degraded. When costs associated with failure are considered, resilient design strategies could prove to be more cost effective over the design life of UWSs.
\end{abstract}

Keywords: flexibility; redundancy; resilience; pipe failure; urban water systems

\section{Introduction}

Although progress has been made towards achieving more sustainable urban water management, urban water systems (UWSs) are increasingly subject to stresses from emerging threats such as urbanisation, climate change and long term asset degradation (Butler et al., 2014; Djordjević et al., 2011; IPCC, 2014a). The impacts of emerging global climate change threats are concentrated in cities and urban areas due to the potentially high density of people, infrastructure, assets and economic activities exposed to these threats. Urbanisation impacts are also exerting significant pressure of existing urban water systems (Urich and Rauch, 2014). As of 2011, 52\% of the global population lives in urban areas and this is projected to grow to between $64-69 \%(5.1-7.1$ billion) by 2050 (IPCC, 2014b). The impact of these threats on existing urban water infrastructure could lead to significant consequences such as reduced customer service levels for water supply and flood protection in the event of unexpected system failures.

Conventional ('Safe') design of urban water systems has been greatly focused on enhancing system reliability that is, minimising the level of service failure frequency over a given system's design life when subject to standard loading (Butler et al., 2014; Jung et al., 2014; Park et al., 2013). However, 'Safe' design approaches eliminate vital attributes such as buffer and redundant capacity that could enable the system to minimise failure magnitude and duration when subjected to exceptional conditions that lead to failure (Hassler and Kohler, 2014; Watt and Craig, 1986; Wildavsky, 1988). It is therefore argued that embedding resilience in UWSs is key to minimising their vulnerability to the emerging threats and to maintaining acceptable customer service levels in cities that they serve (C) IWA Publishing 2015. The definitive peer reviewed and edited version of the article is published in Water Science \& Technology: 
(Blackmore and Plant, 2008; Butler et al., 2014; Lansey, 2012). Extensive literature on concepts and definitions of resilience has been led by ecological system research in which resilience is interpreted as a measure of a system's ability to persist by maintaining its basic structure and function (system integrity) when subject to shocks or disturbances (Holling, 1996). In contrast to ecological systems which exhibit dynamic and multiple stability domains, engineering systems are intentionally designed to provide continuous (uninterrupted) services to society in an efficient manner (Blackmore and Plant, 2008; Holling, 1996; Park et al., 2013). Consequently, the goal of engineering system resilience is essentially to ensure continuity and efficiency of system function during or after occurrence of failure (Butler et al., 2014; Lansey, 2012; Park et al., 2013).

This paper builds on recent work on Safe \& SuRe Water Management that seeks to ensure that urban water systems are designed not only for safe (reliable) provision of services during normal (standard) loading conditions but also to be more resilient to unexpected or exceptional loading conditions (Butler et al., 2014). Resilience is defined as the "the degree to which the system minimises level of service failure magnitude and duration over its design life when subject to exceptional conditions" (Butler et al., 2014). By utilising the Safe \& SuRe approach, urban water systems can be designed to minimise the level of service failure magnitude and duration when subjected to both standard and exceptional conditions. However, guidelines or standards for operationalising resilience in specific urban water systems or sub-systems are still lacking, necessitating further investigation (Butler et al., 2014).

This paper therefore focuses on preliminary testing of both promising resilience characterisation methods and potential resilience-enhancing strategies. To achieve this, model simulations are carried out using a simplified synthetic water distribution system (WDS) and a synthetic urban drainage system (UDS) modelled in EPANET v2.0 (Rossman, 2000) and the Storm Water Management Model, SWMM (Rossman, 2010) respectively to investigate system performance under pipe failure conditions. Adaptation strategies in which flexibility and redundancy attributes are enhanced are tested with the aim of minimising the magnitude and duration of level of service failure, and outline costs associated with each strategy are quantified.

\section{Strategies for enhancing resilience in urban water systems}

Potential strategies for enhancing resilience in UWSs are widely known and practised. They can be broadly categorized in three ways: mitigation, adaption and coping (Butler et al., 2014). In this work, the focus is placed on adaptation as an intervention strategy for enhancing UWS resilience. Adaptation entails targeted actions or adjustments carried out in a specific system in response to actual or anticipated threats in order to minimize failure consequences (IPCC, 2014a; Jones and Preston, 2011). Adaptation is used in this paper to refer to local responses to increasing threats such as modifying specific attributes of the system to enhance its capacity to minimize the magnitude and duration of failure to both standard (i.e. to increase system reliability) and exceptional loading conditions (i.e. to increase general or design resilience). General resilience is used in this context to refer to the state of the system that enables it to limit failure duration and magnitude to any threat (Butler et al., 2014; Hassler and Kohler, 2014).

It is postulated in this work that by implementing adaptation strategies in a specific water system, both reliability and resilience could be enhanced. This could be achieved by altering the system configuration to enhance its flexibility and redundancy properties. Flexibility is defined as inbuilt system capability to adjust or reconfigure so as to maintain acceptable performance levels when subject to multiple (varying) loading conditions (Spiller et al., 2015; Vugrin et al., 2010). Flexibility can be increased in a given system through intentional one-off or phased interventions that enhance 
inbuilt system attributes such as flatness (less system hierarchy), buffering capacity (head room), homeostasis (feedbacks) and omnivory (diversification) (Butler et al., 2014; Hassler and Kohler, 2014; Watt and Craig, 1986; Wildavsky, 1988). It could also be increased by ensuring that more resources (e.g. trained repair crews or emergence water supplies) are readily available at any given time to facilitate rapid response to an unexpected failure event (Butler et al., 2014; Hassler and Kohler, 2014; Lansey, 2012). Based on this, flexibility could in principle be increased in a given UWS through use of spatially distributed (decentralized) systems (e.g. Sitzenfrei et al., 2013), modular systems (e.g. Spiller et al., 2015) or through provision of back-up capacity (e.g. Ahern, 2011; Cabinet Office, 2011).

Redundancy on the other hand refers to the degree of overlapping function in a system that permits the system to change by allowing vital functions to continue while formerly redundant elements take on new functions (Watt and Craig, 1986; Wildavsky, 1988). In UWSs, redundancies could be multiple elements or components providing similar functions, to minimize failure propagation through the system or to enable operations to be diverted to alternative parts of the system during exceptional loading conditions (Ahern, 2011; Cabinet Office, 2011; NIAC, 2009).

Table 1 provides examples of potential adaptation strategies that could in principle (a priori) improve UWS flexibility and redundancy properties. However, it is still unclear how each of these adaptation options actually enhances the resilience a given UWS in the event of unexpected system failures (Butler et al., 2014; Ofwat, 2012; Park et al., 2013). In this study therefore, a new resilience analysis applied is applied to characterize the resilience of case study UWSs and to quantify the effect of implementing a range of adaptation strategies on enhancement of system resilience.

Table 1: Examples of potential adaptation strategies

\begin{tabular}{lll}
\hline Urban water sub-system & \multicolumn{2}{c}{ General (design) resilience attribute } \\
\cline { 2 - 3 } & Flexibility & Redundancy \\
\hline Water distribution system & $\begin{array}{l}\text { Pipe replacement (critical pipes) } \\
\text { Looping (network reconfiguration) }\end{array}$ & $\begin{array}{l}\text { Increase storage tank size } \\
\text { Parallel pipes }\end{array}$ \\
& Back-up pumps & \\
\hline Urban drainage system & Distributed source control & Add centralized storage tanks \\
& Roof disconnection & Pipe replacement \\
& Rain water harvesting & Parallel pipes \\
& Multi-functional urban spaces & \\
\hline
\end{tabular}

\section{Study approach}

The conventional UWS design and rehabilitation approach is to build reliable systems that can achieve expected customer service levels under normal or standard loading conditions (Butler et al., 2014; Jung et al., 2014). Reliability-based approaches such as least cost design formulations ensure that systems are designed to satisfy minimum acceptable service levels within given standard range of operation conditions but may eliminate vital redundancies that are required to meet the required customer services levels when system loading exceed normal conditions (Jung et al., 2014; Lansey, 2012) It is now recognized that UWSs should not only be reliable but also resilient to unexpected or exceptional loading conditions. In this work, the resilience of a given UWS is illustrated through assessment of the effect of failure scenarios that could occur when the system is subjected to a wide range of unexpected threats (e.g. Johansson, 2010). Pipe failure is considered for the two case studies. Figure 1 illustrates the study approach based on middle (failed) state-based global resilience analysis (Johansson, 2010) that is adopted in this research. The developed approach enables system resilience to be assessed without the need to quantify the probability of occurrence of threats that lead to system failure (Johansson, 2010). In the case of the WDS, single pipe failure is investigated using a simplified synthetic network that requires rehabilitation due to increased water demand. Pipe (C) IWA Publishing 2015. The definitive peer reviewed and edited version of the article is published in Water Science \& Technology: 
failure is used to model potential structure failure modes in WDSs that lead to pipe breakage such as pipe bursts, leakages and collapse (Kleiner and Rajani, 2001). The effect of two rehabilitation strategies involving pipe replacement on resilience is evaluated and the capital costs associated with each strategy computed.

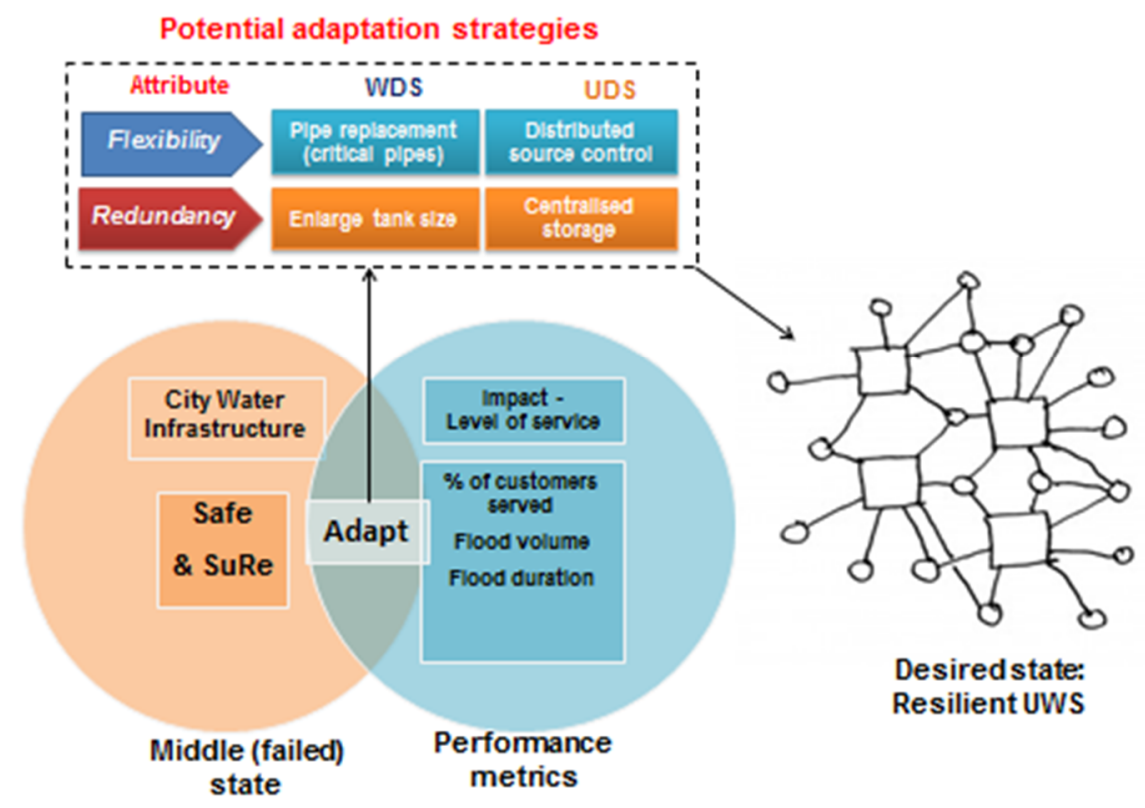

Figure 1: Study approach based on middle (failed) state global resilience analysis of UWSs (Butler et al., 2014; Johansson, 2010). The figure on the right that illustrates the desired resilient UWS is adopted from Mehaffy and Salingaros (2013).

In the UDS case study, cumulative pipe failure is investigated using a synthetic network that requires rehabilitation to minimize the flooding magnitude and duration. Pipe failure is used to model potential structural failure modes in UDSs that include pipe collapse, blockages and bed load sediment deposition (Butler and Davies, 2011). Two adaptation strategies in which redundancy and flexibility may be enhanced are investigated, namely, downstream centralised storage (CS) and upstream distributed storage (DS) strategies respectively. The effect of the strategies on minimising the loss of system functionality is evaluated and the discounted total cost of each strategy is evaluated considering a design life of 50 years.

\section{Results and discussion}

\section{Case study 1 - water distribution system}

WDS resilience is illustrated by testing the performance of the system under single pipe failure scenarios. The resulting loss of system functionality for a given UWDS can be quantified using social and economic impacts such as loss of supply or repair costs. A WDS is said to be resilient (to pipe failure) if it can maintain the required level of service during the considered failure scenarios.

A synthetic WDS reported in Todini (2000) is used in this work (Figure 2a). The system requires rehabilitation due to water demand increase. The system consists of 1 storage tank, 9 nodes and 15 links. The actual pipe lengths are as follows: the pipe connecting the reservoir (node 0) is $2000 \mathrm{~m}$ long, the contour pipes are all $1000 \mathrm{~m}$ long and all the internal pipes connected to node 9 are $1210 \mathrm{~m}$ (C) IWA Publishing 2015. The definitive peer reviewed and edited version of the article is published in Water Science \& Technology: 
long. Two rehabilitation strategies are compared. Strategy B (Figure 2b) is a design scenario in which single pipe failure scenarios are not initially considered during the design but occur during the period of operation. In Figure 2c, single pipe failure scenarios are taken into consideration and flexibility is introduced into the system by ensuring that for each node at least two possible paths (links) with larger diameters are provided (Strategy C). Table A.1 provides details of the design scenario including demand and required minimum head for each node. Further details on the network configuration and the design scenario considered are provided in Todini (2000).

The capital costs of all the considered strategies are calculated according to diameter classes using the cost data provided in Table A.2. Given the significant variability of land costs in different city contexts, land costs are not included in the capital cost calculations (e.g. Farmani et al., 2005; Todini, 2000). Model simulations are carried out in EPANET to investigate the effect of single pipe failure scenarios on the ability of the UDS to minimize the resulting loss of system functionality. Loss of system functionality is quantified by computing the total water demand at the failed nodes. Comparing the two strategies described, strategy $\mathrm{C}$, in which failure scenarios are considered at the design stage, cost slightly more $(1.9 \%)$ but enables the system to cope with all single pipe failure events, i.e. no loss of supply. Contrarily, one third of customers would be unserved in the other strategies. The reason why strategy $\mathrm{C}$ results in a more resilient WDS is because there are at least two paths formed by large pipes (i.e. diameter $\geq 203 \mathrm{~mm}$ ) to each node. This ensures that the system capacity is better allocated compared to the other two designs.

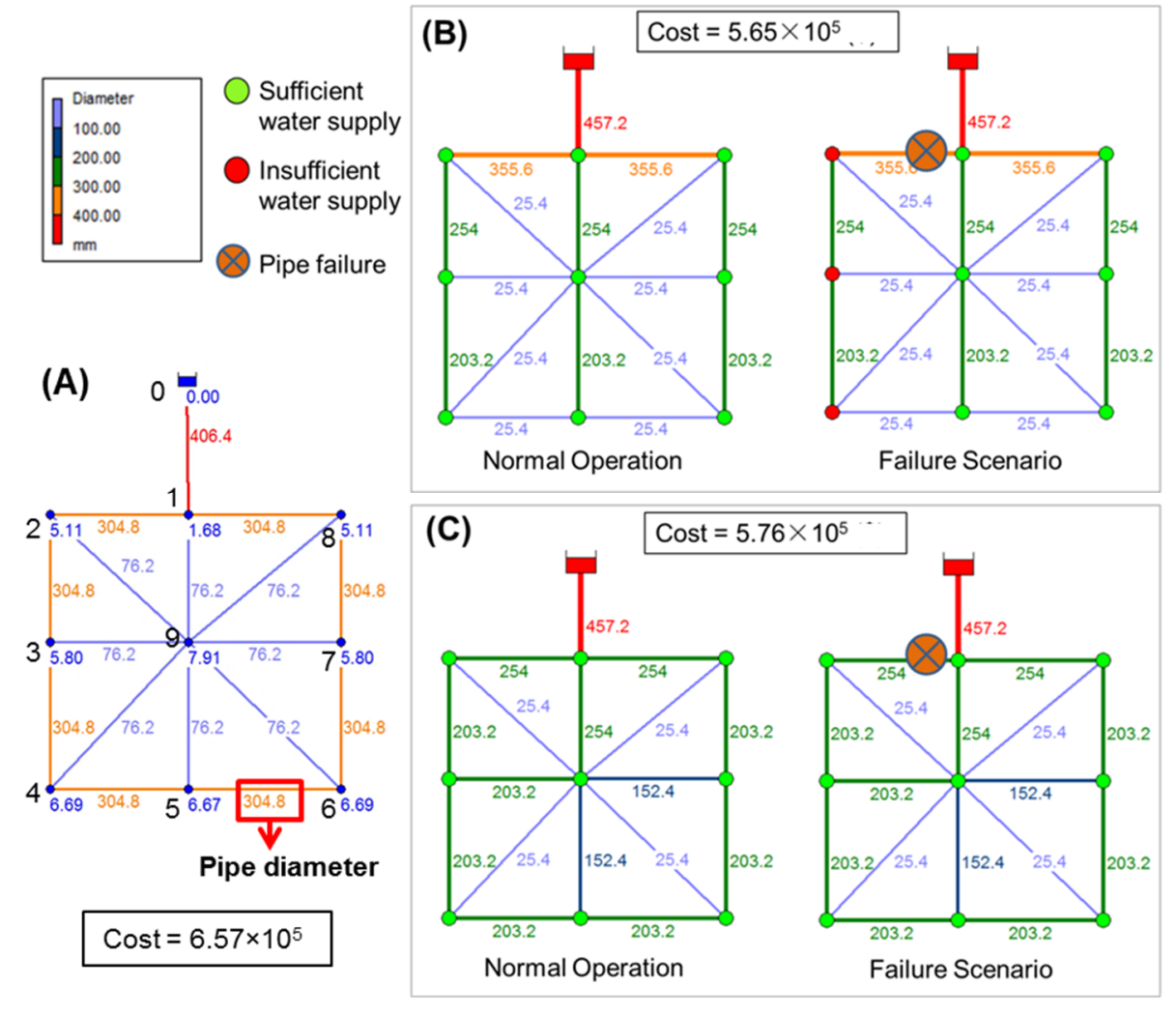

Figure 2: (A) Original design of the water distribution system; (B) Rehabilitation strategy without failure scenarios considered (reproduced from Todini, 2000); (C) Rehabilitation strategy with failure scenarios considered.

\section{Case study 2 - Urban drainage system}

The existing UDS with no storage (business as usual, BAU) requires rehabilitation because its current configuration leads to unacceptable surface flooding during extreme rainfall events (Figure 
3a). This system is a baseline configuration in which the pipes provide the hydraulic capacity of the system with no storage devices. The system consists of 26 nodes and 25 links with diameters ranging from $600 \mathrm{~mm}$ to $1500 \mathrm{~mm}$, and slopes ranging from $0.5-2.25 \%$ and has been designed based to satisfactory convey flows resulting from an observed 100 minute rainfall event with a total depth $=$ $66.2 \mathrm{~mm}$ (Sliuzas et al., 2013) with no flooding at any node in the system. The UDS drains a total catchment area of 22.5 hectares with an average slope of $0.5 \%$ and percentage imperviousness of $25 \%$. In addition, two adaptation strategies are modelled and used to test their effect on enhancement of system resilience: (a) Centralised storage (CS) strategy: a large storage tank is introduced upstream of pipe $\mathrm{C} 24$ to minimise downstream flooding by enhancing peak flow attenuation effects (Figure 3b) and (b) Distributed storage (CS) strategy: 9 spatially distributed upstream storage tanks (same total storage volume as the CS strategy) are introduced at the outlets of each sub catchment to enhance flexibility at critical points in the network at sub-catchment level (Figure 3c).

(a)

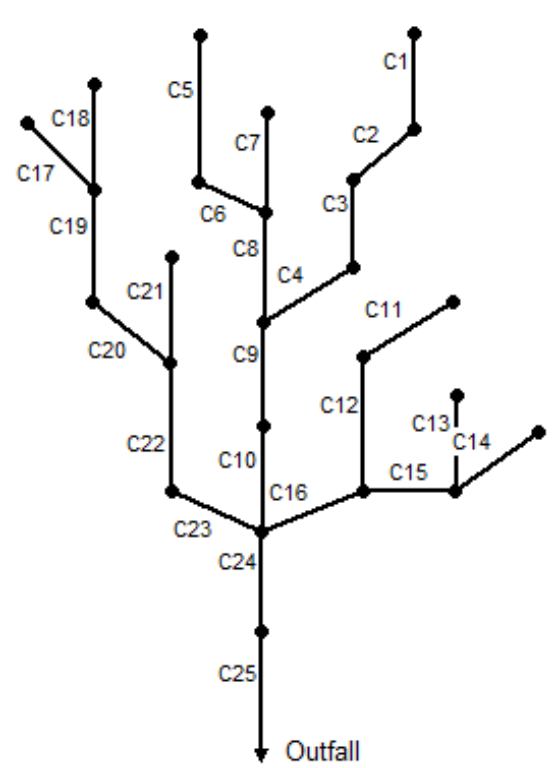

(b)

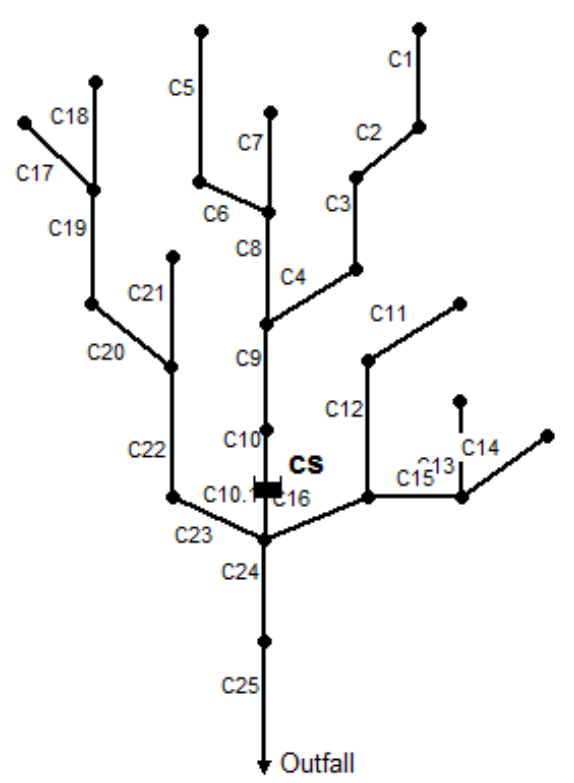

(c)

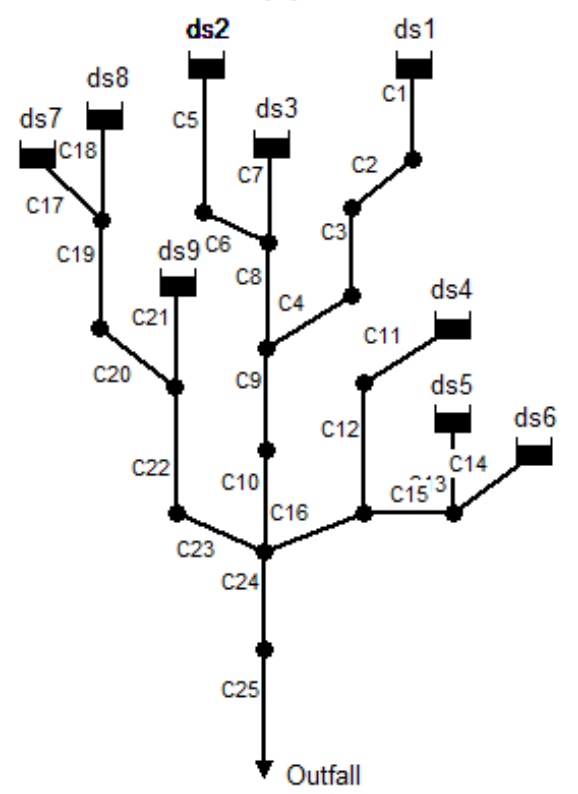

Figure 3: Layout of (a) Existing UDS with no storage (BAU); (b) UDS with centralised (downstream) storage (c) UDS with upstream distributed storage.

Model simulations are carried out in SWMM v5.1 to investigate the effect of cumulative pipe failure on resulting loss of functionality (surface flooding) for the three system configurations are represented in Figure 3. Flooding is simply modelled using a flood cone with all surface flows returning to the node from which they discharged (Rossman, 2010). In order to test the performance of the BAU system during failure conditions, model simulation is carried out using an up scaled extreme rainfall event with a total depth of $141 \mathrm{~mm}$ and duration of 100 minutes (i.e. change factor of 2.14 is applied to scale the event return period, $T$ from 2 to 50 years). Simulation results indicate that pipes in existing system (initial state) experiences hydraulic overloading that leads to flooding in most parts of the network (total flood volume of $10,910 \mathrm{~m}^{3}$ and duration of 42 minutes). A high peak flow rate of $6.95 \mathrm{~m}^{3} / \mathrm{s}$ is attained in the downstream pipes (C24) after a simulation period of 88 minutes (Figure 4). 


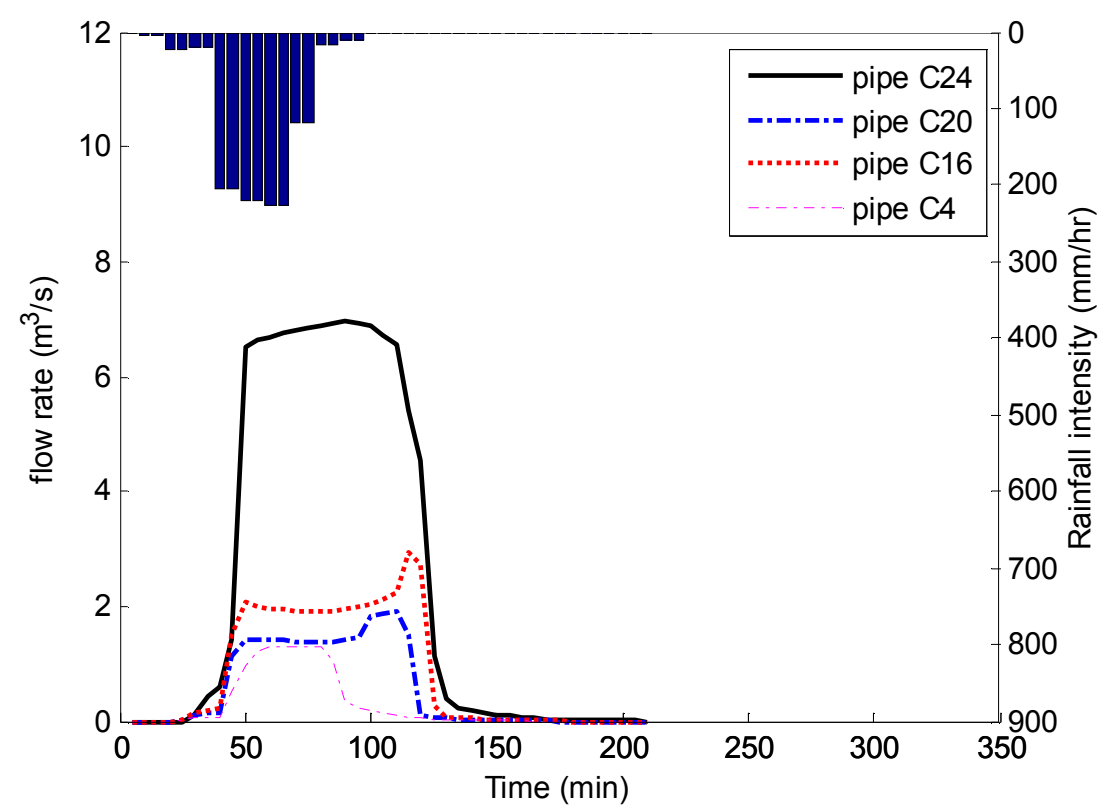

Figure 4: Simulated flow rates in pipe C24, C20, C16 and C4 for the existing UDS with no storage (BAU)

The system is subjected to increasing (cumulative) pipe failure scenarios (stress) in order to evaluate global performance (loss of system functionality) using total flood volume and mean nodal flood duration as key performance indicators. Pipe failure is modelled by significantly reducing pipe diameters, $D_{P}$ in the model from their initial values (non-failed state) to a very small value of $1 \mathrm{~mm}$ in order to model pipe failure (failed state), while maintaining hydraulic connectivity required for the solution of the flow equations. A simulation run is carried out for the first random pipe failure scenario, then additionally, a second pipe is randomly failed and a second simulation run carried out. This is done cumulatively until all pipes in the network have failed. In addition, using the proposed approach, the effect of implementing the proposed adaptation strategies on improvement of global resilience is investigated. For comparison of the strategies, the discounted cost, $P V C_{T}$ for each strategy is computed considering a design life of 50 years, using cost functions presented in Appendix Table A.3. Similarly, given the significant local city specific factors that influence land acquisition, land cost is excluded from the capital cost calculations (Swan and Stovin, 2007).

The results of the BAU case in Figure 5 indicate that cumulative pipe failure leads to a rather high increase in the total flood volume and mean flood duration. This suggests that occurrence of pipe failures in UDSs lead to significant loss of system functionality, which progressively increases with increasing pipe failure levels. The occasional 'plateaus' in the simulated flooding impacts (Figure 5) are attributed to failure of less critical pipes (e.g. an upstream pipe conveying low flows) with leads to minimal increase in the simulated flood volume and duration despite further increase pipe failure levels. The rapid increase in simulated flooding impacts is attributed to failure of more critical pipes. Globally, the results suggest that the existing system exhibits low of levels of resilience to cumulative pipe failure. 
(a) Flood volume

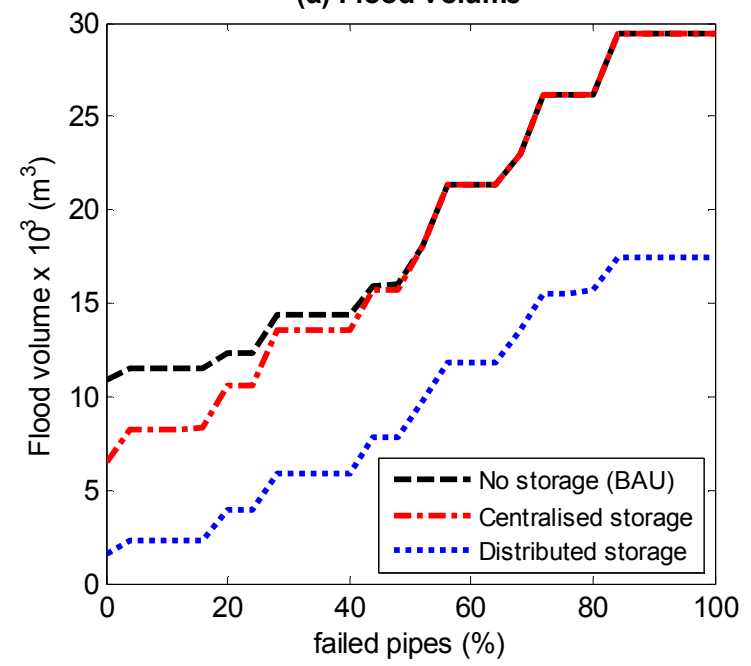

(b) Flood duration

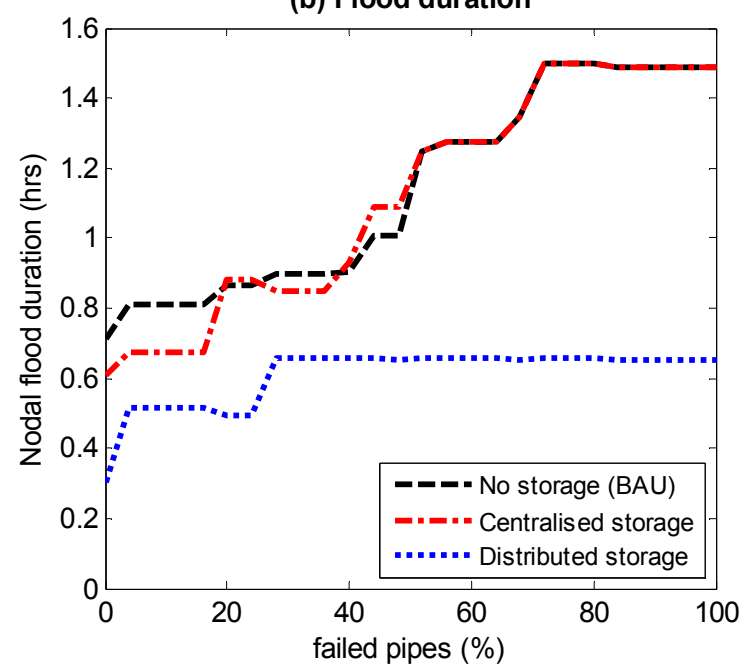

Figure 5: Effect of cumulative pipe failure on (a) flood volume (b) mean duration of nodal flooding

Overall, a total of 78 simulations are carried out and a summary of the results of the analysis is provided in Table 2 .

Table 2: UDS performance indicators considering cumulative pipe failure scenarios

\begin{tabular}{|c|c|c|c|c|c|c|}
\hline \multirow[b]{2}{*}{ Statistic } & \multicolumn{3}{|c|}{ Flood volume $\left(\times 10^{3} \mathrm{~m}^{3}\right)$} & \multicolumn{3}{|c|}{ Mean duration of nodal flooding (hrs) } \\
\hline & $\begin{array}{c}\text { No } \\
\text { storage }\end{array}$ & $\begin{array}{c}\text { Centralised } \\
\text { storage }\end{array}$ & $\begin{array}{c}\text { Distributed } \\
\text { storage }\end{array}$ & $\begin{array}{c}\text { No } \\
\text { storage }\end{array}$ & $\begin{array}{c}\text { Centralised } \\
\text { storage }\end{array}$ & $\begin{array}{l}\text { Distributed } \\
\text { storage }\end{array}$ \\
\hline Mean failure & 19.30 & 18.37 & 9.64 & 1.14 & 1.12 & 0.61 \\
\hline Standard deviation & 6.98 & 8.05 & 5.84 & 0.29 & 0.33 & 0.09 \\
\hline Min failure & 12.33 & 10.32 & 3.80 & 0.85 & 0.79 & 0.52 \\
\hline Max failure & 26.28 & 26.42 & 15.48 & 1.43 & 1.45 & 0.70 \\
\hline Mean reduction & & $\begin{array}{c}4.8 \% \\
{[-0.5-16.3 \%]}\end{array}$ & $\begin{array}{c}50.1 \% \\
{[41.1-69.2 \%]}\end{array}$ & & $\begin{array}{c}1.9 \% \\
{[-0.9-6.7 \%]}\end{array}$ & $\begin{array}{c}46.7 \% \\
{[38.8-51.4 \%]} \\
\end{array}$ \\
\hline
\end{tabular}

Implementing the centralised storage strategy results in a slight reduction in the flood volume and mean nodal flood duration; with the reduction being effective at low $(<48 \%)$ pipe failure levels. Globally, the strategy results in minimal reduction of the total flood volume and mean flood duration of $4.8 \%$ and $1.9 \%$ respectively when compared to the BAU case. From the results, it can be interpreted that the centralised storage strategy leads to minimal reduction of the loss of system functionality magnitude and duration and consequently a slight improvement in system resilience to cumulative pipe failure.

Implementing the distributed storage strategy results in a significant reduction in total flood volume at all pipe failure levels implying the effect of cumulative pipe failure (stress) on loss of system functionality magnitude (strain) is reduced. In the case of the flood duration, the strain on the system increases to a maximum of 0.66 hours and remains almost constant when the cumulative pipe failure level exceeds $32 \%$, which suggests that increasing the spatial distribution of control options in upstream parts of the network ensures optimal global performance during pipe failure scenarios. This design strategy is therefore more resilient to cumulative pipe failure when compared to the other two strategies as demonstrated by the significant mean reduction in the total flood volume and duration of nodal flooding of $50.1 \%$ and $46.7 \%$ respectively. The results of the discounted cost calculations are presented in Figure 6. 


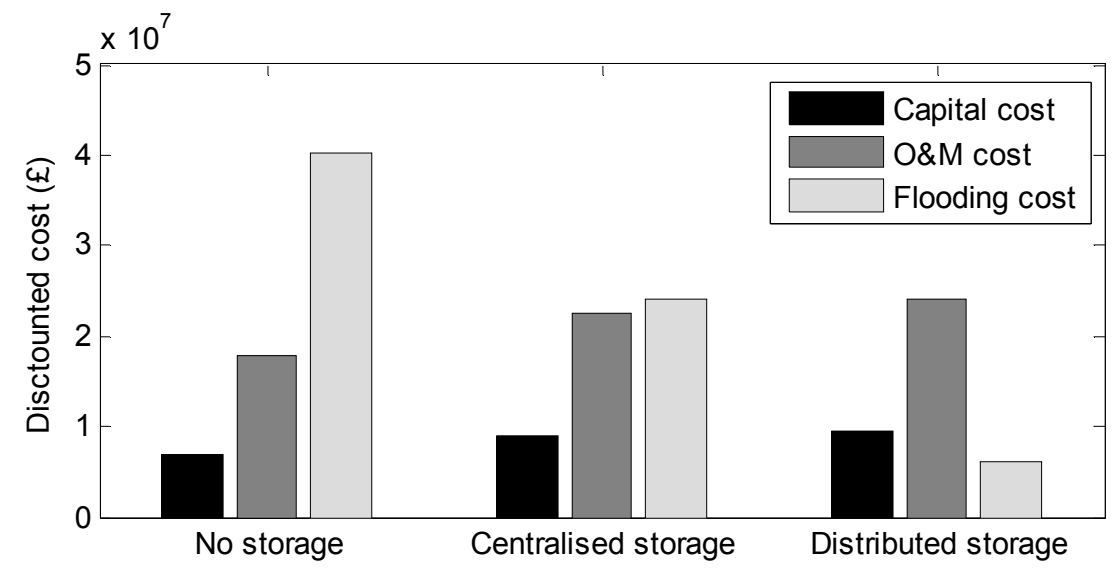

Figure 6: Discounted total cost of UDS design strategies

The capital costs of the centralised and distributed storage strategies are higher by $27 \%$ and $35 \%$ respectively due to the addition of storage devices. When direct tangible flooding costs are taken into consideration, the centralised storage strategy leads to $14.5 \%$ reduction in discounted total costs. On the other hand, the distributed storage strategy results into a $39.2 \%$ reduction in discounted total cost, which is attributed to the reduced direct tangible flooding costs.

\section{Conclusions}

The resilience of urban water systems to unexpected threats can be enhanced by embedding redundancy and flexibility in system design, retrofit or rehabilitation. In this study, redundancy is enhanced by introducing a centralised storage tank (UDS case). Flexibility on the other hand is enhanced by increasing network connectivity (WDS case) and use of distributed storage tanks (UDS case). Simplified synthetic networks are used to investigate ways to evaluate resilience in existing systems and to test effectiveness of implementing various adaptation strategies in minimising the loss of system functionality and cost during pipe failure scenarios.

In the WDS case study, although the strategy in which flexibility is enhanced (strategy C) initially increases capital costs by $1.9 \%$, it results in minimal loss of system functionality and consequently ensures adequate customer service levels during single pipe failure scenarios. In the UDS case study, the distributed storage strategy minimises the total flood volume and mean flood duration by $50.1 \%$ and $46.7 \%$ respectively and hence is more resilient to cumulative pipe failure. Although this strategy has higher initial capital costs due to the additional cost of distributed storage tanks, it results in a significant reduction of $39.2 \%$ in the total discounted total costs when direct tangible surface flooding costs over the system's design life are taken into consideration.

This study has demonstrated that loss of system functionality during exceptional loading conditions can be minimised if failure scenarios are taken into consideration during UWS design (i.e. resilient design). The study results also suggest that enhancement of system flexibility attributes, for example through increasing connectedness and spatial distribution of control options enhances the ability of UWSs to minimise the resulting loss of functionality during unexpected system failures. The study also indicates that by taking into account the cost of failure, resilient design strategies could prove to be more cost effective over the design life of UWSs. It is concluded that embedding resilience in UWSs provides a promising and potentially cost effective approach to maintain acceptable customer service levels during unexpected failures and to contribute to more sustainable water management in cities in view of emerging threats. Further research using the presented approach is recommended to investigate resilience in existing real world systems and to test the effectiveness of strategies that 
enhance spatial distribution and connectedness properties such as city scale dual-purpose rainwater harvesting systems (e.g. DeBusk, 2013) and multifunctional green infrastructure (e.g. Ahern, 2011).

\section{Acknowledgement}

This work is financially supported through a UK Commonwealth $\mathrm{PhD}$ scholarship awarded to the first author. This work has also been supported through the UK Engineering \& Physical Sciences Research Council (ESPRC) funded Safe \& SuRe research fellowship (EP/K006924/1) awarded to last author. 


\section{Appendix}

Table A.1: Head and demand values for the WDS case study

\begin{tabular}{lcccccccccc}
\hline Node & 0 & 1 & 2 & 3 & 4 & 5 & 6 & 7 & 8 & 9 \\
\hline Head $(\mathrm{m})$ & 200 & 197 & 193 & 192 & 191 & 191 & 191 & 192 & 193 & 189 \\
Demand $\left(\mathrm{m}^{3} / \mathrm{h}\right)$ & -180 & 20 & 20 & 20 & 20 & 20 & 20 & 20 & 20 & 20 \\
\hline
\end{tabular}

Table A.2: Diameter classes and cost of pipes

\begin{tabular}{|c|c|c|c|c|c|c|c|c|c|c|c|c|c|c|}
\hline Diameter $(\mathrm{mm})$ & 25.4 & 50.8 & 76.2 & 101.6 & 152.4 & 203.2 & 254 & 304.8 & 355.6 & 406.4 & 457.2 & 508 & 558.8 & 609.6 \\
\hline Cost (units) & 2 & 5 & 8 & 11 & 16 & 23 & 32 & 50 & 60 & 90 & 130 & 170 & 300 & 550 \\
\hline
\end{tabular}

Table A.3: Capital and operation and maintenance cost functions for an urban drainage network

\begin{tabular}{lll}
\hline Cost ('000 £) & Cost Equation & Remarks/References \\
\hline Discounted total cost $\left(P V C_{T, y}\right)$ & $\sum_{t=0}^{t=x} C_{T} /\left(1+\frac{r}{100}\right)^{t}$ & $r=3.5 \%$ for initial 30 yrs, then r $=3.0 \%$ \\
Total cost $\left(C_{T}\right)$ & $C_{P}+C_{M}+C_{L}+C_{S T}+C_{O M}+C_{T F}$ & Includes cost of failure \\
Pipe cost $\left(C_{p}\right)$ & $0.455 D_{P}^{1.72}$ & Barreto, (2012) \\
Pipe laying cost $\left(C_{L}\right)$ & $70 L p D_{P} d_{p}$ & Unit cost of $£ 70 / \mathrm{m}$ length/m diameter/m depth \\
Manhole cost $\left(C_{M}\right)$ & $300 d_{m}$ & Unit cost of $£ 300 /$ manhole \\
Storage tank cost $\left(C_{S T}\right)$ & $738.33 V_{S T}^{0.88}$ & Barreto (2012) \\
O \& M cost $\left(C_{O M}\right)$ & $0.1 \times\left(C_{P}+C_{L}+C_{M}+C_{S T}\right)$ & $10 \%$ of total capital costs \\
Flooding cost $\left(C_{T F}\right)$ & $\sum_{t=0}^{t=x} V_{T F} \cdot f_{c} \cdot \bar{R}_{t}$ & Only direct tangible flooding costs considered \\
Flood occurrence probability $\left(\bar{R}_{t}\right)$ & $1-\left(1-\frac{1}{T}\right)^{t}$ & Butler and Davies (2011) \\
\hline
\end{tabular}

Where $r$ is the discount rate; $t$ a given time period during the system design life of $x$ years; $D_{p}$ the pipe diameter; $L_{p}$ the pipe length; $d_{p}$ the pipe depth; $d_{m}$ the manhole depth; $V_{S T}$ the storage volume $\left(\mathrm{m}^{3}\right) ; V_{T F}$ the total flood volume; $f_{c}$ direct tangible flooding cost ( $£ /$ cubic meter of flooding); $T$ the rainfall return period; and $P V C_{T, y}$ the discounted total cost of a implementing a given adaptation strategy, $y$. 


\section{References}

Ahern J. 2011 From fail-safe to safe-to-fail: sustainability and resilience in the new urban world. Landscape, 100, 341-343.

Blackmore, J. M. and Plant, R. A. J. 2008 Risk and Resilience to Enhance Sustainability with Application to Urban Water Systems. Water Resources Planning and Management, 134(3), 224 $-233$.

Barreto C.W.J. 2012 Multi-objective optimization for urban drainage rehabilitation. $\mathrm{PhD}$ Thesis, UNESCO IHE Institute for Water Education, Delft University of Technology.

Blackmore, J. M., \& Plant, R. A. J. 2008 Risk and Resilience to Enhance Sustainability with Application to Urban Water Systems. Water Resources Planning and Management, 134(3), 224 $-233$

Butler D. and Davies J. W. 2011 Urban Drainage. Spon Press, London.

Butler, D., Farmani, R., Fu, G., Ward, S., Diao, K., \& Astaraie-Imani, M. 2014 A new approach to urban water management: Safe and SuRe. Procedia Engineering, 89, 347-354. doi:10.1016/j.proeng.2014.11.198

Cabinet Office 2011 Keeping the country running: Natural hazards and infrastructure, London.

DeBusk, K.M., 2013. Rainwater Harvesting: Integrating Water Conservation and Stormwater Management. PhD Thesis, North Carolina State University, Raleigh, North Carolina.

Djordjević S., Butler D., Gourbesville P., Mark O., and Pasche E. 2011 New policies to deal with climate change and other drivers impacting on resilience to flooding in urban areas: the CORFU approach. Environmental Science \& Policy, 14, 864-873.

Farmani, R., Walters, G. A., and Savić, D. A. 2005 Trade-off between total cost and reliability for Anytown water distribution network. Water Resources Planning and Management, 131(3), 161171.

Hassler, U. and Kohler, N. 2014 Resilience in the built environment. Building Research \& Information, 42(2), 119-129.

Holling, C. S. 1996 "Engineering Resilience versus Ecological Resilience” In: Engineering within ecological constraints, P. Schulze (ed.), Washington DC, USA, National Academy Press, 31-44

IPCC 2014a Chapter 8 - Urban Areas. In Climate Change 2014: Impacts, Adaptation and Vulnerability - Contributions of the Working Group II to the Fifth Assessment Report (eds.), C. B. Field, V. R. Barros, D. J. Dokken, K. J. Mach, M. D. Mastrandrea, T. E. Bilir, M. Chatterjee, K. L. Ebi, Y. O. Estrada, R. C. Genova, B. Girma, E. S. Kissel, A. N. Levy, S. MacCracken, P. R. Mastrandrea, and L.L White. Cambridge University Press, Cambridge and New York, 1113.

IPCC 2014b Summary for Policy Makers In Climate Change 2014: Impacts, Adaptation and Vulnerability - Contributions of the Working Group II to the Fifth Assessment Report (eds.), C. B. Field, V. R. Barros, D. J. Dokken, K. J. Mach, M. D. Mastrandrea, T. E. Bilir, M. Chatterjee, K. L. Ebi, Y. O. Estrada, R. C. Genova, B. Girma, E. S. Kissel, A. N. Levy, S. MacCracken, P. R. Mastrandrea, and L.L White. Cambridge University Press, Cambridge and New York, 1-32.

Johansson J. 2010 Risk and Vulnerability Analysis of Interdependent Technical Infrastructures Addressing Socio-Technical Systems. PhD Thesis, Department of Measurement Technology and Industrial Electrical Engineering, Lund University.

Jones R.N and Preston B. L. 2011 Adaptation and risk management. Wiley Interdisciplinary Reviews: Climate Change, 2(2), 296-308.

Jung, D., Kang, D., Kim, J. H., \& Lansey, K. (2014). Robustness-based Design of Water Distribution Systems. Journal of Water Resources Planning and Management, 140(11). doi:10.1061/(ASCE)WR.1943-5452.0000421

Kleiner Y and Rajani B. 2001 Comprehensive review of structural deterioration of water mains: statistical models. Urban Water 3, 131-150. 
Lansey, K. 2012 Sustainable, robust, resilient, water distribution systems. In 14th Water Distribution Systems Analysis Conference, Engineers Australia, 1-18.

Mehaffy M and Salingaros N. A. 2013 Toward Resilient Architectures 1: Biology Lessons, 1-7. http://www.metropolismag.com/Point-of-View/March-2013/Toward-Resilient-Architectures-1Biology-Lessons/.

NIAC 2009 Critical infrastructure resilience - Final report and recommendations. US National Infrastructure Advisory Council Report.

Ofwat (2012) Resilience - outcomes focused regulation. Principles for resilience planning, Birmingham.

Park, J., Seager, T. P., Rao, P. S. C., Convertino, M., and Linkov, I. (2013) Integrating risk and resilience approaches to catastrophe management in engineering systems. Risk Analysis, 33(3), $356-367$.

Rossman, L W. 2010 Storm Water Management Model - User's Manual Version 5.0. Cincinnati, Ohio.

Rossman, LW. 2000 EPANET 2 User's manual. Cincinnati, Ohio.

Sitzenfrei, R., Möderl, M., and Rauch, W. (2013) Assessing the impact of transitions from centralised to decentralised water solutions on existing infrastructures - Integrated city-scale analysis with VIBe. Water research, 47, 7251-7263.

Sliuzas, R., Jetten, V., Flacke, J., Lwasa, S., Wasige, J., and Pettersen, G. 2013 Flood Risk Assessment, Strategies and Actions for Improving Flood Risk Management in Kampala, Kampala.

Spiller, M., Vreeburg, J. H. G., Leusbrock, I., and Zeeman, G. (2015) Flexible design in water and wastewater engineering - Definitions, literature and decision guide. Journal of Environmental Management, 149, 271-281.

Swan, A. D. and Stovin, V. R. 2007 Retrofit SuDS — cost estimates and decision-support tools. Proceedings of the ICE - Water Management, 160(WM4), 207-214.

Todini E. 2000 Looped water distribution networks design using a resilience index based heuristic approach. Urban Water, 2(2), 115-122.

Urich, C. and Rauch, W. 2014 Exploring critical pathways for urban water management to identify robust strategies under deep uncertainties. Water research, 66, 374-389.

Vugrin, E. D., Warren, D. E., Ehlen, M. A., and Camphouse, C. R. 2010 A framework for assessing resilience of infrastructure and economic systems. In Sustainable and resilient critical infrastructure systems. (eds.) K. Gopalakrishnan and S. Peeta. Springer-Verlag, Berlin Heidelberg, 77-110.

Watt K and Craig, P. 1986 System stability principles. Systems Research, 3(4), 191-201.

Wildavsky A. 1988 Search for safety, New Brunswick, Transaction Publishers. 